\title{
A human mutant CD4 molecule resistant to HIV-1 binding restores helper T-lymphocyte functions in murine CD4-deficient mice
}

\author{
Dong-Ku Kim ${ }^{1,5}$, Tahara-Hanaoka Satoko ${ }^{2}$, \\ Nobutsuna Shinohara ${ }^{3}$ and Hiromitsu Nakauchi ${ }^{4}$ \\ ${ }^{1}$ Cell and Gene Therapy Research Institute \\ College of Medicine, Pochon CHA University \\ CHA General Hospital \\ Seoul 135-081, Korea \\ ${ }^{2}$ Department of Immunology \\ Institute of Basic Medical Sciences \\ University of Tsukuba \\ Ibaraki, Japan \\ ${ }^{3}$ Department of Obstetrics and Gynecology \\ Kitasato University School of Medicine \\ Sagamihara, Japan \\ ${ }^{4}$ Laboratory of Stem Cell Therapy \\ Center for Experimental Medicine \\ Institute of Medical Science \\ University of Tokyo \\ Tokyo 108-8639, Japan \\ ${ }^{5}$ Corresponding author: Tel, 82-2-3468-3394; \\ Fax, 82-2-3468-3264; E-mail, dokukim@cha.ac.kr
}

Accepted 28 July 2006

Abbreviations: BDF1, (C57BL/6 XDBA/2)F1; KO, knockout; muthCD4, mutant human $\mathrm{CD} 4$; $\mathrm{TG}$, transgenic

\begin{abstract}
CD4 is a cell surface glycoprotein that acts as a co-receptor for the $\mathrm{T}$ cell antigen receptor by binding to a non-polymorphic portion of MHC molecules. CD4 also functions as a receptor for human immunodeficiency virus type-I (HIV-1) because the viral envelope glycoprotein gp120 binds to CD4 with a high affinity. We have previously demonstrated that introduction of mutations into CD4 abolished the binding of gp120 and prevented HIV-1 from entering cells and spreading. However, whether introduction of such mutations into CD4 causes decreased binding to MHC and loss of function is yet to be determined. We generated transgenic mouse lines by injecting a mutant human CD4 (muthCD4) gene under a murine CD4 enhancer/promoter to ensure tissue and stage specific expression. To exclude the influence of endogenous murine CD4, transgenic
\end{abstract}

mice were crossed with murine CD4-targeted mice to produce muthCD4 transgenic mice lacking endogenous CD4 (muthCD4TG/KO mice). In these mice, T lymphocytes expressing muthCD4 expanded and matured in the thymus and were present in the spleen and lymph nodes. They also activated B cells to mount an antibody response to a T-dependent antigen. The results from this study suggest that a human variant of CD4 modified to be resistant to HIV-1 binding can rescue the signaling for $\mathrm{T}$ cell develop ment in the thymus in vivo, having helper $\mathrm{T}$ cell functions. Thus, further characterization of muthCD4 molecules should open the way to new HIV treatment modalities.

Keywords: antigens, CD4; aquired immunodefiency syndrome; CD4-positive T-lymphocytes; HIV-1; mice, transgenic; T-lymphocytes, helper-inducer

\section{Introduction}

Acquired immune deficiency syndrome (AIDS) is a rapidly expanding global pandemic with more than 10 million people worldwide infected with human immunodeficiency virus type-1 (HIV-1). Considering that the number of infected individuals, particularly children, has been increasing, there is an urgent need to develop curative treatments for AIDS. Despite numerous intense research efforts, HIV-1 infection still remains an incurable and fatal disease. One of the main reasons is the high rate of mutation in the viral genome (Coffin, 1995; Manaski et al., 1995), which generates drug-resistant strains of HIV-1 (Moutouh et al., 1996) making it difficult to develop an effective drug-based therapy. This situation necessitates the development of innovative therapies, such as gene therapy, for this deadly disease. Some such therapies have recently reached clinical trials (Poeschla et al., 1996; Sanhadji et al., 1997).

The glycoprotein CD4, which functions as a T cell co-receptor molecule (Biddison et al., 1982; Krensky et al., 1982) by binding to MHC class II, plays a pivotal role in HIV-1 infection (Clayton et al., 1989; Roby and Axel, 1990). CD4 has four immunoglobulin-like domains (D1-D4) (Maddon et al., 1985; Williams and Barelay, 1988) and binding of the 
HIV's gp120 protein to the D1 portion of CD4 appears to be necessary for the initial stage of viral infection (Landau et al., 1988; Peterson et al., 1988). Soluble forms of CD4 (sCD4) can bind to gp120 and prevent viral entry into cells (Rosenstein et al., 1990). Therefore, in vivo administration of SCD4 was considered as a possible means of inhibiting the spread of HIV-1. However, the results from clinical trials were disappointing since continuous expression of high levels of these soluble receptors in vivo was required for effective inhibition of HIV-1 infection.

With the advancement of homologous recombination technology, generation of $T$ lymphocytes expressing a genetically modified form of CD4 that does not bind viral gp120 may prove useful. Since gp120 binds to CD4 through the D1 domain within CD4, mutation of that site abolishes this binding and hinders HIV-1 from entering cells. Recently, we characterized the region in human CD4 responsible for binding to gp120 and constructed a mutant human CD4 by replacing sequences encoding three amino acids (43Phe, 45Thr, 46Lys) with sequences corresponding to murine CD4 (Val, Lle, Arg) (Siddiqi et al., 1997). The mutant CD4 had little, if any, binding activity to gp120 in vitro. To further characterize the function of the mutant human CD4 molecule in vivo, we generated transgenic mice and analyzed the effects of the mutant human CD4 on the development and function of $T$ lymphocytes, as well as susceptibility to HIV-1 infection.

We have investigated whether murine CD4 T lymphocytes in the process of thymocyte development are rescued by over-expression of human mutant CD4 under the control of a murine CD4 promoter in murine CD4 null mutant mice. We observed that $\mathrm{T}$ lymphocytes expressing human mutant CD4 on the cell surface developed in the thymus and appeared in the peripheral lymphoid organs, including lymph nodes and the spleen. Furthermore, human mutant CD4 T lymphocytes mediated the expected biological effects of helper $T$ cells. Notably, they induced immunoglobulin production in B lymphocytes.

\section{Materials and Methods}

\section{Transgene construction}

Mutant human CD4 (muthCD4) cDNA was constructed by site-directed mutagenesis according to the method of Kunkel (1985). In muthCD4, amino acids 43,45 , and 46 within the D1 domain of human CD4 were replaced with residues corresponding to $\mathrm{mu}$ rine CD4 sequences (43:Phe to $\mathrm{Val}, 45: \mathrm{Thr}$ to Ile, 46:Lys to Arg). After introducing the mutations, sequences were confirmed by DNA sequencing. A 1.7 kb Xhol-fragment containing muthCD4 was excised from the plasmid $p E n e o A F$, and then subcloned into a plasmid vector downstream of the murine CD4 enhancer/promoter. For oocyte injection and generation of transgenic mice, a $10.4 \mathrm{~kb}$ insert containing muthCD4 cDNA and the murine CD4 enhancer/promoter was excised from the plasmid and non-essential sequences were removed using the Notl enzyme.

\section{Generation of transgenic mice}

BDF1 mice were purchased from Clear Japan (Tokyo, Japan). CD4 $4^{-1-}$ mice (C57BL/6) were purchased from Jackson Laboratories (Bar Harbor, ME). To generate transgenic mice, the human mutant CD4 construct containing the murine CD4 enhancer and promoter was injected into pronuclei of male murine $\mathrm{CD} 4^{-/-}$ and female BDF1 mice. PCR screening of founders was based on detection of the transgene in DNA from peripheral blood using primers specific for human CD4 (sense: GGATCACCTTTGACCTGAAGAAC, antisense: GAGGAGTCTCTTGATCTGAGA). PCR was performed for 30 cycles with denaturation for $1 \mathrm{~min}$ at $94^{\circ} \mathrm{C}$, annealing at $60^{\circ} \mathrm{C}$ for $45 \mathrm{~s}$, and extension at $72^{\circ} \mathrm{C}$ for $1 \mathrm{~min}$ using DNA prepared with Instagene Matrix (BioRad). MuthCD4 transgenic mouse founders with heterogeneous murine CD4 ${ }^{-1+}$ were backcrossed to murine $\mathrm{CD} 4^{-/-}$targeted mice to obtain human mutant CD4 transgenic mice lacking homogenous murine CD4. Screening of murine CD4 mice was performed by flow cytometry with a murine CD4 monoclonal antibody (L3T4, PharMingen). Expression of the transgene was confirmed by both RT-PCR and flow cytometry. For cell membrane staining, a monoclonal antibody (OKT4, Coulter) that binds to the membrane proximal region of human CD4 was used. All mice were maintained and bred in a specific pathogen-free environment.

\section{Flow cytometric analysis}

For flow cytometric analysis of thymocytes, splenocytes, lymph nodes, and peripheral blood mononuclear cells, anti-mouse CD3-biotin, anti-mouse TCR $\alpha \beta$-biotin, anti-mouse CD8-PE (PharMingen), anti-human CD3-biotin (DAKO, Japan), and antihuman CD4 (OKT4; Coulter) monoclonal antibodies were used. Biotinylated Abs were visualized using either PE or APC-labeled streptavidin (PharMingen). Approximately $1 \times 10^{6}$ cells were stained with antibodies for $30 \mathrm{~min}$ on ice and then washed with the staining medium containing PBS (-), 3\% FCS and $0.1 \%$ sodium azide. Cells were resuspended in a staining medium containing propidium iodide (PI: 5 $\mu \mathrm{g} / \mathrm{ml}$ ) to stain dead cells. Human PBMC, human 
CD4 transgenic mice, and C57BL/6 mice were used as positive and negative controls.

A

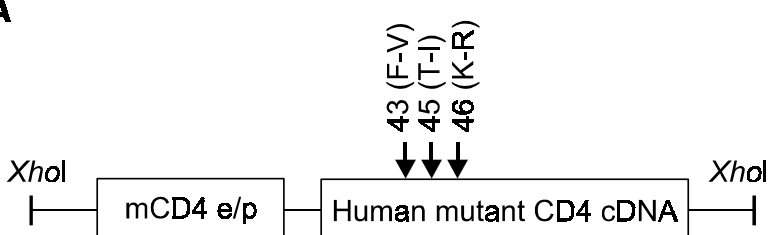

B

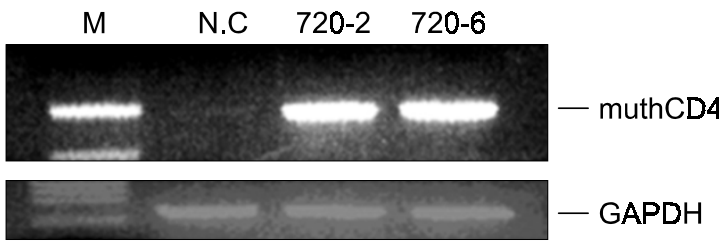

Figure 1. Generation of human mutant CD4 transgenic mice. (A) The construct carrying human mutant CD4 CDNA under the control of a murine CD4 enhancer and promoter is shown. The arrow indicates the mutant amino acid of human CD4 and the corresponding mouse CD4 amino acid. (B) PCR analysis in two representative transgenic mice was performed with specific primers for human CD4.

\section{Antibody production assay}

Mice were immunized intraperitoneally with $100 \mu \mathrm{g}$ OVA in PBS (-) per mouse and bled at days 0 and 15 after injection. Goat anti-mouse IgG antibody conjugated with alkaline phosphatase (AP) was obtained from Sigma and used for the ELISA. Substrates were contained in the Ampli $Q$ kit from DAKO, Japan. Sera were analyzed for ovalbumin (OVA) specific antibodies by ELISA using 96 -well plates coated with $10 \mu \mathrm{g} / \mathrm{ml}$ of OVA overnight at room temperature. Plates were washed 2 times with PBS (-) and then blocked with PBS containing $1 \% \mathrm{BSA}$ for $30 \mathrm{~min}$, then incubated with serial dilutions of serum for $2 \mathrm{~h}$ at room temperature. After washing with PBS (-), goat antimouse IgG alkaline phosphatase-conjugated secondary antibody was applied for $2 \mathrm{~h}$ at room temperature followed by addition of the substrate for $1 \mathrm{~h}$ with shaking at room temperature. ELISA assay results involved measuring the absorbance on a plate reader at a wavelength of $490 \mathrm{~nm}$.

\section{Results}

Generation of human mutant CD4 transgenic mice To obtain specific expression of a human mutant
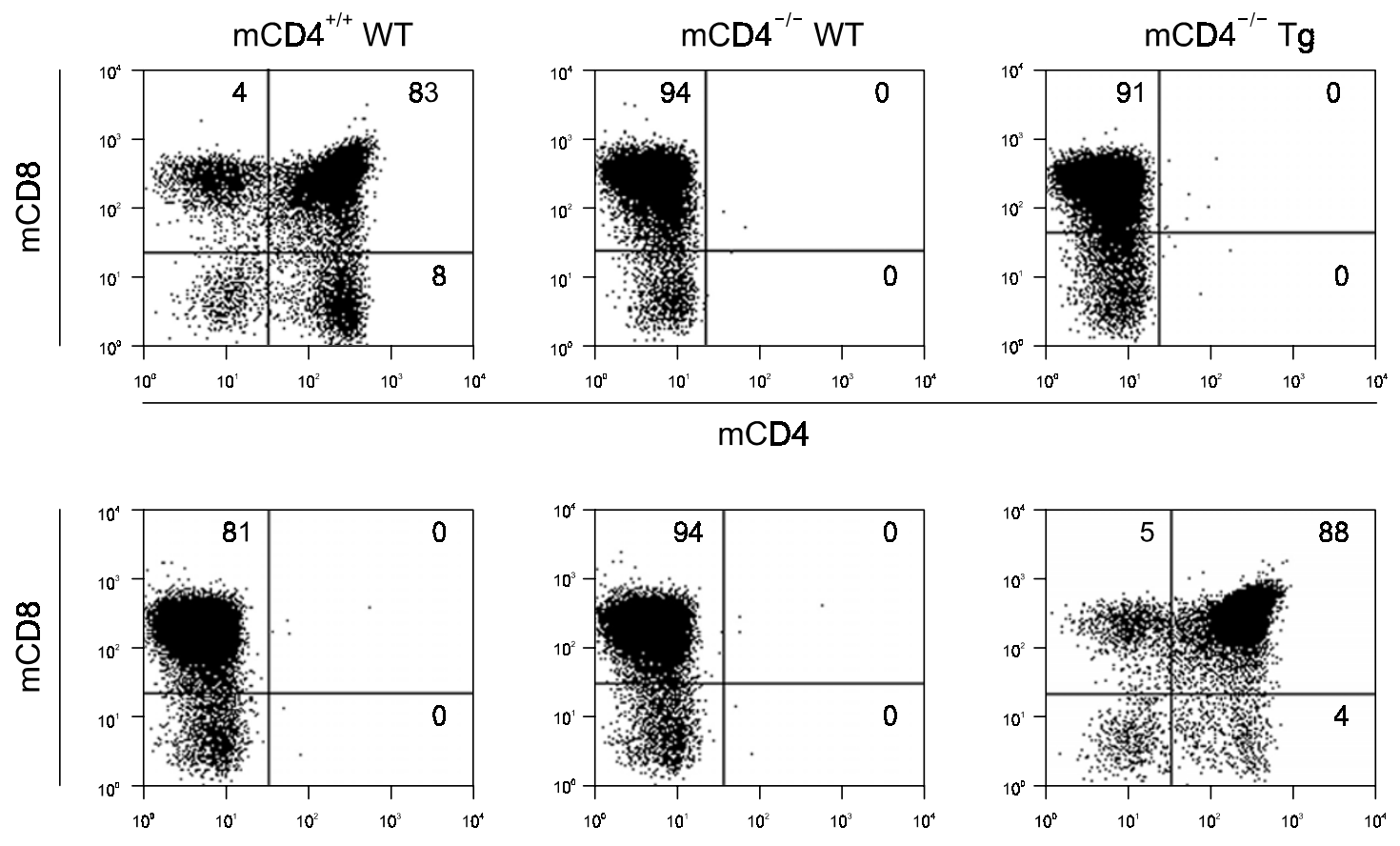

hCD4 (OKT4)

Figure 2. Flow cytometric analysis of thymocytes in transgenic mice. Thymocytes from indicated mice, namely human muthCD4 non-transgenic murine $\mathrm{CD} 4$ wild type mouse $\left(\mathrm{mCD}^{+/+} \mathrm{WT}\right)$, human muthCD4 non-transgenic murine $\mathrm{CD} 4$ mutant mouse $\left(\mathrm{mCD} 4^{-/-} \mathrm{WT}\right)$, and human muthCD4 transgenic mouse lacking endogenous murine $\mathrm{CD} 4\left(\mathrm{mCD} 4^{-/-} \mathrm{Tg}\right)$, were stained with anti-mouse CD4 (L3T4), anti-human CD4 (OKT4), and anti-mouse CD3 antibodies and analyzed by flow cytometry. 
CD4 gene (muthCD4) in murine CD4 lymphocytes, we constructed a human mutant CD4 cDNA transgene that included three amino acid point mutations under the control of the murine CD4 enhancer/ promoter region (Figure $1 \mathrm{~A}$ ). PCR analysis using genomic DNA obtained from peripheral blood identified 10 transgenic founder mice carrying muthCD4 cDNA out of a total 67 offspring (Figure 1B). In seven of those ten mice, muthCD4 mRNA was detectable in peripheral blood by RT-PCR (data not shown). Flow cytometric analysis using a monoclonal antibody specific for human CD4 confirmed varying degrees of cell surface expression of muthCD4 in PBMC derived from the seven mice. In one of the seven founder mice, the expression level of the muthCD4 transgene was comparable to the level of endogenous murine CD4, whereas very low expression levels of the muthCD4 transgene were found in the other transgenic mice. A muthCD4 transgenic/mCD4 knockout mouse (muthCD4TG/KO) was generated by crossing F1 progeny from this founder mouse with CD4 null mutant mice, then these mice were backcrossed five times into the $\mathrm{C} 57 \mathrm{BL} / 6$ mouse strain to obtain inbred mice for further biological study.

\section{Development of helper $\mathrm{T}$ cells expressing mutant human CD4}

To examine the development of helper $T$ cells in muthCD4TG/KO mice, thymocytes and splenocytes were analyzed for expression of mouse CD3, mouse CD8, and OKT4 by flow cytometry. In the thymus of muthCD4TG/KO mice, muthCD4/CD8 double positive (DP) and muthCD $4^{+} C D 8^{-}$single positive (SP) T cells were present as normal. Flow cytometric analysis indicated that the DP T cell percentage in the thymus of muthCD4TG/KO mice was higher than in normal mice $(88.2 \pm 2.8 \%$ vs. $83.4 \pm 4.6 \%)$. On the other hand, in muthCD4 Tg/Ko mice, the ratio of muthCD4 SP cells was nearly half that of normal mice $(3.9 \pm 1.5 \%$ vs. $8.0 \pm 3.2 \%)$ (Figure 2$)$. The development of CD8 ${ }^{+} \mathrm{CD} 4^{-} \mathrm{T}$ cells was not affected in transgenic mice. The absolute number of thymocytes and splenocytes was similar in muthCD4TG/ $\mathrm{KO}$ mice $\left(4.5 \pm 0.3 \times 10^{7}\right.$ cells $)$ and control mice $\left(4.8 \pm 0.3 \times 10^{7}\right.$ cells $)$. As shown in Figure 3 , the proportion of $\mathrm{CD}^{+} \mathrm{SP} \mathrm{T}$ cells was greatly reduced compared to control mice $(11 \pm 1.5 \%$ vs. $35 \pm 5.4 \%$ in $\mathrm{CD}^{+} \mathrm{T}$ cells). A corresponding reciprocal increase was observed in $\mathrm{CD}^{+} \mathrm{SP} T$ cells $(81.5 \pm 1.6 \%$ vs. $62 \pm 8.5 \%)$. These frequencies are similar to the cell numbers previously reported in human CD4 trans-
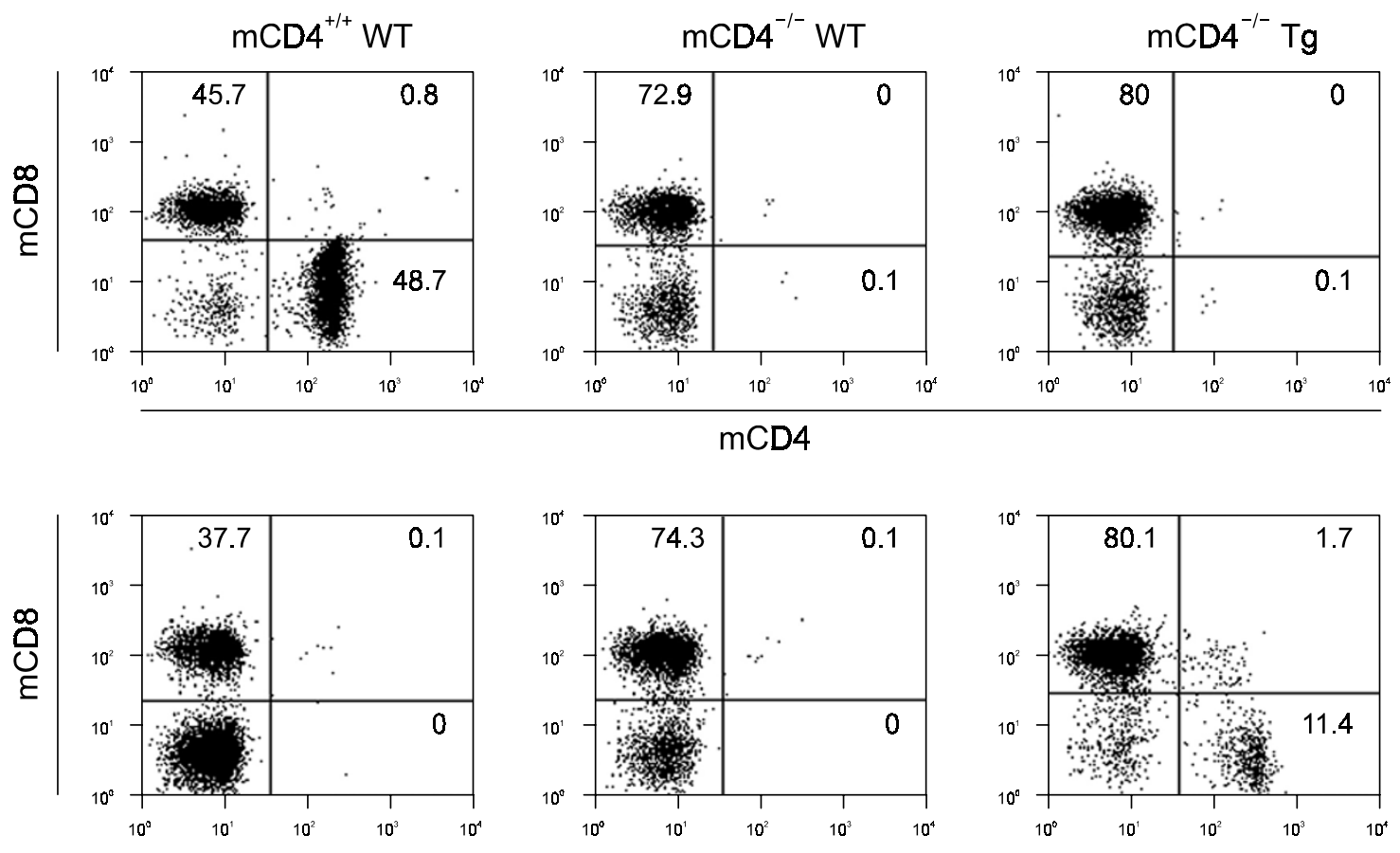

hCD4 (OKT4)

Figure 3. Development of human mutant CD4 T lymphocytes in the spleen of transgenic mice. Splenocytes from indicated transgenic mice 6-8 weeks old were stained with each antibody and analyzed with flow cytometry. The data was shown the generation of muthCD4 T lymphocytes in the spleen. 
genic/mCD4KO mice (Law et al., 1994). We obtained similar results in the lymph nodes and peripheral blood. The numbers of muthCD $4^{+} \mathrm{T}$ cells in $\mathrm{CD}^{+} \mathrm{T}$ cells were much lower than the number of $\mathrm{CD}^{+} \mathrm{T}$ cells in muthCD4TG/KO mice. In the lymph nodes, human muthCD4 ${ }^{+} \mathrm{T}$ cell expression of TCR $\alpha \beta$ was similar to normal mice (Figure 4). These results strongly suggest that $T$ cells expressing muthCD4 on the cell surface developed via a normal positive selection mechanism in the thymus.

\section{MuthCD4 ${ }^{+} \mathrm{T}$ cells support $\mathrm{B}$ cell immune response} $\mathrm{CD} 4^{-/-}$mice are deficient in the production of $\mathrm{T}$ celldependent antibody responses. To determine whe-

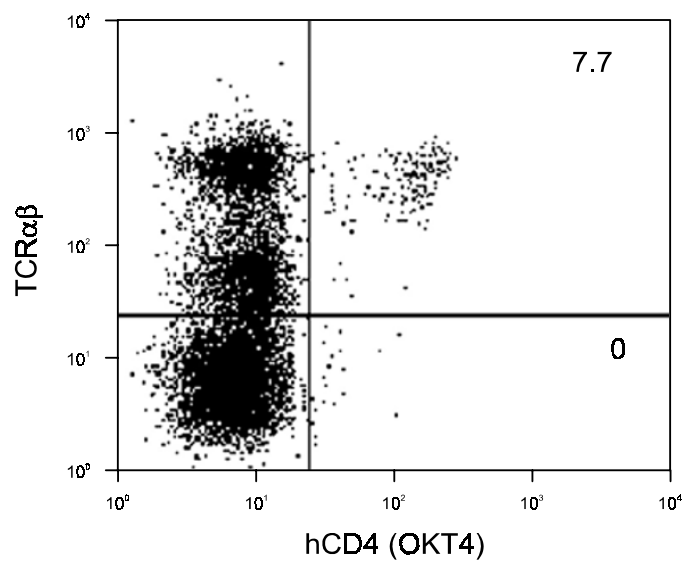

Figure 4. Expression of TCR $\alpha \beta$ in human mutant $C D 4$-expressing mature $T$ cells. Lymph node cells were isolated from human muthCD4 transgenic mice lacking endogenous murine CD4 expression and stained with TCR $\alpha \beta$ and human CD4 (OKT4) antibodies for analysis of cell surface expression. Representative data from flow cytometric analyses are shown. ther this defect can be rescued by expression of muthCD4, mice were immunized intraperitoneally with $100 \mu \mathrm{l}$ of OVA in PBS (-). After 15 days, sera were collected and assayed for the presence of OVA-specific antibodies using isotype-specific ELISA. As shown in Figure 5, in transgenic mice the level of total IgG antibodies specific for OVA was restored to the level in normal mice. These results indicate that the muthCD4 $\mathrm{T}$ cells of transgenic mice can enable $\mathrm{B}$ cell antibody production in vivo.

\section{Gp120 binding assay with muthCD4 $\mathrm{T}$ cells}

In vitro binding assays have demonstrated that the muthCD4 variant used to generate transgenic mice

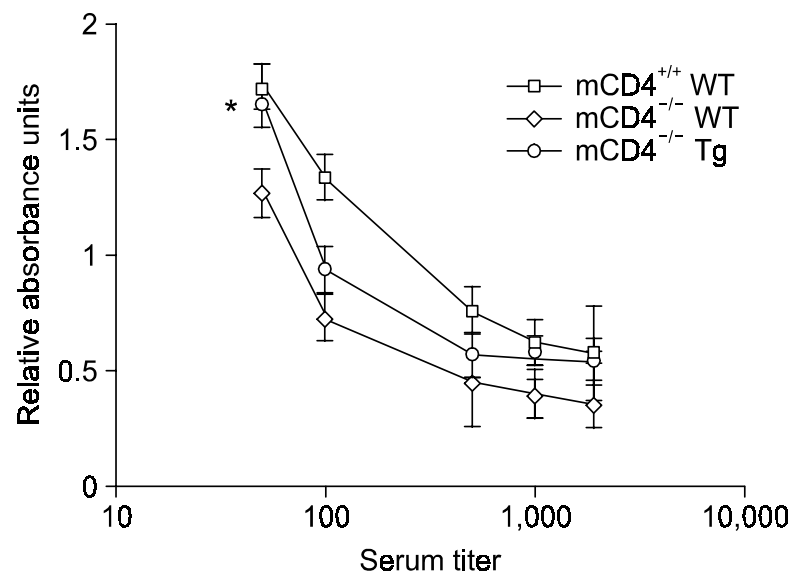

Figure 5. Restoration of antibody response in vivo by human mutant CD4 T cells. Mice were immunized intraperitoneally with OVA $(100 \mu \mathrm{g})$ and sera were taken 15 days after primary immunization. Serum from indicated mice was diluted to the indicated level for ELISA and the presence of anti-OVA specific mouse IgG antibodies was determined for groups of four mice. Significant differences between $\mathrm{CD} 4^{-1-} \mathrm{WT}$ and $\mathrm{CD}^{-/-} \mathrm{Tg}$ mouse; ${ }^{*} P<0.05$.

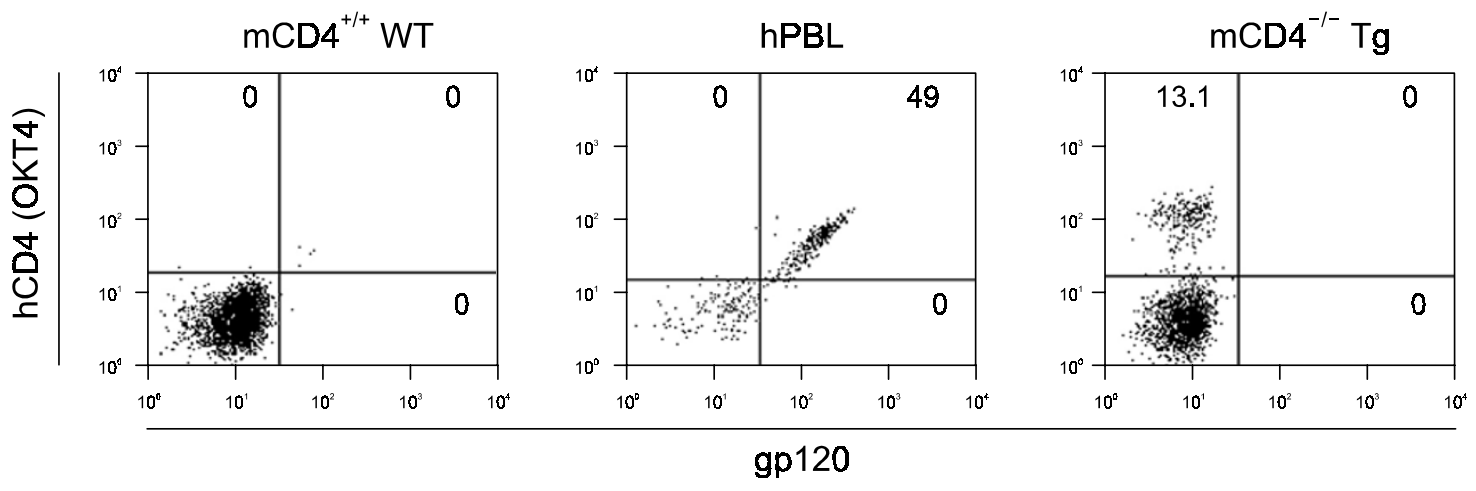

Figure 6. gp120 binding assay. Mononuclear cells from peripheral blood of human mutant CD4 transgenic mice (hmCD4Tg), human CD4 transgenic mice (hCD4Tg), and human controls were stained with gp120 conjugated with FITC and with CD3-biotin antibodies. After washing, CD4 (OKT4)-PE and streptavidin-APC were added, then flow cytometry was performed. The data represent the population of $\mathrm{T}$ cells in the CD3 gate. 
fails to bind to the HIV envelope protein gp120. To confirm whether muthCD4 on the T cells of transgenic mice binds to gp120 in vivo, a gp120 binding assay was performed. Cells obtained from peripheral blood of muthCD4TG/mCD4KO mice and murine $\mathrm{CD} 4^{+/+}$mice as well as human peripheral blood, were incubated with recombinant gp120 and antibodies to human CD3 and CD4, then subjected to flow cytometric analysis. Figure 6 illustrates the lack of binding of gp120 to T cells from human PBMC and human CD4 transgenic mice. This result is consistent with our previous in vitro binding data that indicated mutant CD4 did not bind to the HIV gp120 protein.

\section{Discussion}

The cell surface glycoprotein CD4 forms an attractive target for prevention of HIV infection because initiation of HIV infection involves the binding of the viral protein gp120 to the D1 domain of human CD4 (Landau et al., 1988). We have previously reported that introduction of mutations into CD4 produces a marked decrease in gp120 binding affinity and prevents entry of HIV into the cells (Siddiqi et al., 1997). However, we had difficulty in assessing whether such mutant CD4 can bind to MHC and function as a co-receptor. By crossing human CD4 transgenic mice with mouse CD4 null mutant mice, it has been shown that human CD4 can interact with mouse MHC molecules (Killeen et al., 1993). Thus, we used this method to examine the functional capacity of our mutant CD4. The muthCD4 transgenic mice were crossed with CD4 null mutant mice to exclude the influence of endogenous murine CD4. Transgenic/knockout mice (muthCD4TG/mCD4KO) have $T$ cells that express only muthCD4. Furthermore, human muth $\mathrm{CD} 4^{+} \mathrm{T}$ lymphocytes were able to activate $B$ cells to produce antibodies against a $T$ cell dependent antigen (OVA). Results obtained from the present study strongly suggest that muthCD4 effectively substitutes for endogenous murine CD4.

The proportion of muthCD $4^{+}$SP cells was lower in the muthCD4 transgenic mouse thymus than in the control mouse thymus. A decrease in the ratio of $\mathrm{CD}^{+} \mathrm{SP}$ to $\mathrm{CD}^{+} \mathrm{SP}$ was also observed in the peripheral blood and the spleen. Killeen et al. observed that introduction and expression of wild type human CD4, driven by a murine CD4 enhancer/promoter unit, restored $70 \%$ of $C D 4^{+}$SP cells in CD4 null mutant mice (1993). Using wild type human CD4 driven by a murine CD3 promoter, incomplete restoration of $\mathrm{CD}^{+} \mathrm{SP}$ cell numbers has been reported (Law et al., 1994), possibly reflecting low expression of the introduced human CD4 gene. This situation could also be due to low affinity binding of human CD4 to murine MHC class II molecules. A single amino acid mutation assay revealed that amino acid residues 45 and 46 of CD4 were key residues for interaction with $\mathrm{MHC}$ class II and that mutation of this region resulted in conformational changes of the CD4 molecule (Ryu et al., 1990; Fleury et al., 1991; Moebius et al., 1992). Thus, the amino acid changes that we introduced may also have lowered the binding affinity to mouse MHC class II molecules. In addition, we observed a similar, relatively lower muthCD4 ${ }^{+} \mathrm{T}$ cell population in muthCD4 transgenic mice by flow cytometric analysis.

Despite incomplete restoration of $\mathrm{CD}^{+} \mathrm{SP}$ cell numbers compared with normal mice, these mature muthCD $4^{+} \mathrm{T}$ cells had the ability to activate $\mathrm{B}$ cells and mount an antibody response to a $T$ cell dependent antigen (OVA), suggesting that muthCD4 interacted with murine MHC class II and led to signals essential for helper $T$ cell function. Our results showed that muthCD4 ${ }^{+} \mathrm{T}$ cells can function sufficiently as a substitute for murine endogenous CD4 in vivo. Within the CD4 molecule, the binding site for gp120 appears to be distinct from the site for MHC class II molecules (Lamarre et al., 1989a; $1989 \mathrm{~b})$. It is likely that binding of CD4 and MHC class II molecules takes place in a broad area encompassing the D1 region whereas the site for gp120 binding is restricted to a specific region within D1. By crossing muthCD4TG/mCD4KO transgenic mice carrying the human MHC class II gene in an endogenous MHC class II null background, we should be able to determine whether our conclusion holds for muthCD4 and human class II MHC molecules.

Our ultimate goal is to construct a functional CD4 molecule resistant to HIV infection for the prevention and treatment of AIDS. Our results indicate that muthCD4 is a candidate molecule for this purpose. Recently, it has been reported that homologous recombination using human embryonic stem cells can be achieved with a highly stable transfection efficiency using electroporetic methods (Thomas and James, 2003). This report suggests that the targeting of muthCD4 for complete prevention of HIV infection may be possible in the near future by manipulation of hematopoietic cells in vitro prior to transplantation into patients. Thus, our pre-clinical studies hold promise for the future development of novel HIV therapeutics.

\section{Acknowledgement}

The authors would like to thank Dr. S. Sawada for providing human CD4 enhancer/promoter gene, and T. 
Morita for FACS operation. This work was supported by grants from the Ministry of Education, Science, Sports and Culture in Japan, by a grant (SC3240) from the Stem Cell Research Center funded by the Korea Ministry of Science and Technology, and by a grant (Code 20050401034790) from the BioGreen 21 Program, Rural Development Administration, Republic of Korea.

\section{References}

Biddison WE, Rao PE, Talle MM, Goldstein G, Shaw S. Possible involvement of the OKT4 molecule in $T$ cell recognition of class II HLA antigen. J Exp Med 1982;156: 1065-76

Clayton LK, Sieh M, Pious DA, Reinherz EL. Identification of human CD4 residues affecting class II MHC versus HIV-1 gp120 binding. Nature 1989;339:548-51

Coffin JM. HIV population dynamics in vivo: implication for genetic variation, pathogenesis, and therapy. Science 1995; 267:483-9

Fleury S, Lamarre D, Meloche S, Ryu SE, Cantin C, Hendrickson WA, Sekaly RP. Mutational analysis of the interaction between CD4 and class II MHC: class II antigens contact CD4 on a surface opposite the gp120-binding site. Cell 1991;66: 1037-49

Killeen N, Sawada S, Littman DR. Regulated expression of human CD4 rescues helper T cell development in mice lacking expression of endogenous CD4. EMBO 1993;12:1547-53

Krensky AM, Reiss CS, Mier JW, Strominger JL, Burakoff SJ. Long-term human cytolytic T-cell lines allospecific for HLADR6 antigen are OKT4 ${ }^{+}$. Proc Natl Acad Sci USA 1982;79: 2365-9

Kunkel TA. Rapid and efficient site specific mutagenesis without phenotypic selection. Proc Natl Acad Sci USA 1985; 82:488-92

Lamarre D, Ashikenazi A, Fleury S, Smith DH, Sekaly RP, Capon DJ. The MHC-binding and gp120-binding functions of CD4 are separable. Science 1989a;245:743-6

Lamarre D, Capon DJ, Karp DR, Gregory T, Long EO, Sekaly RP. Class II MHC molecules and the HIV gp120 envelop protein interact with functionally distinct regions of the CD4 molecule. EMBO J 1989b;8:3271-7

Landau NR, Warton M, Littman DR. The envelope glycoprotein of the human immunodeficiency virus binds to the immunoglobulin-like domain of CD4. Nature 1988;334:159-62

Law YM, Yeung RS, Mamalaki C, Kioussis D, Mark TW. Flavel RA. Human CD4 restores normal T cell development and function in mice deficient in murine CD4. J Exp Med 1994;179: 1233-42

Maddon PJ, Littman DR, Godfrey M, Maddon DE, Chess L, Axel $R$. The isolation and nucleotide sequence of a cDNA encoding the T cell surface protein T4: a new membrane of the immunoglobulin gene family. Cell 1985;42:93-104

Manasky LM, Temin HM. Lower in vivo mutation rate of human immunodeficiency virus type 1 than that predicted from the fidelity of purified reverse transcriptase. J Virol 1995;69: 5087-94

Mizukami T, Fuerst TR, Berger EA, Moss B. Binding region for human immunodeficiency virus (HIV) and epitopes for IHV-blocking monoclonal antibodies of the CD4 molecule define by site-directed mutagenesis. Proc Natl Acad Sci USA 1988;85:9273-7

Moebius U, Clayton LK, Abaraham S, Diener A, Yunis JJ, Harrison SC, Reinherz EL. Human immunodeficiency virus gp120 binding C'C" ridge of CD4 domain I is also involved in interaction with class II histocompatibility complex molecules. Proc Natl Acad Sci USA 1992;89:12008-12

Moutouh, L, Corbeil J, Richman DD. Recombination leads to the rapid emergence of HIV-1 dually resistant mutants under selective drug pressure. Proc Natl Acad Sci USA 1996;93: 6106-11

Peterson A, Seed B. Genetic analysis of monoclonal antibody and HIV binding sites on the human lymphocyte antigen CD4. Cell 1988;54:65-72

Poeschla E, Corbeau P, Wong-Staal F. Development of HIV vectors for anti-HIV gene therapy. Proc Natl Acad Sci USA 1996;93:11395-9

Robey E, Axel R. CD4: Collaboration in immune recognition and HIV infection. Cell 1990;60:697-700

Rosenstein Y, Burakoff S, Herrmann SH. HIV-gp120 can block CD4-class II MHC-mediated adhesion. J Immunol 1990; 144:526-31

Ryu SE, Kwong PD, Truneh A, Poter TG, Arthos J, Rosenberg M, Dai XP, Xuong N, Axel R, Sweet RW, Hendrickson WA. Crystal sturucture of an HIV-binding recombinant fragment of human CD4. Nature 1990;348:419-26

Sanhadji K, Leissner P, Firouzi R, Pelloquin F, Kehrli L, Marigliano M, Calenda V, Ottmann M, Tardy JC, Mehtali M, Touraine JL. Experimental gene therapy: the transfer of Tat-inducible interferon genes protects human cells against HIV-1 challenge in vitro and in vivo in severe combined immunodeficient mice. AIDS 1997;11:977-86

Siddiqi MA, Tachibana M, Ohta S, Ikegami Y, Tahara-Hanaoka $S$, Huang $Y$, Shinohara N. Comparative analysis of the gp120-binding area of murine and human CD4 molecules. J Acqir Immune Defic Syndr Hum Rettrovirol 1997;14:7-12

Thomas PZ. James AT. Homologous recombination in human embryonic stem cells. Nat Biothechnol 2003;21:319-21

Williams AF, Barclay AN. The immunoglobulin superfamilydomains for cell surface recognition. Annu Rev Immunol 1988; 6:381-405 